\title{
Seasonal prediction of Indian summer monsoon: Sensitivity to persistent SST
}

\author{
Sukanta Kumar Das*, Sanjib Kumar Deb, C M Kishtawal and Pradip Kumar Pal \\ Atmospheric and Oceanic Sciences Group, Space Applications Centre, ISRO, Ahmedabad 380 015, India. \\ *Corresponding author.e-mail: sukanta1003@gmail.com sukanta@sac.isro.gov.in
}

In the present study, the assessment of the Community Atmosphere Model (CAM) developed at National Centre for Atmospheric Research (NCAR) for seasonal forecasting of Indian Summer Monsoon (ISM) with different persistent SST is reported. Towards achieving the objective, 30-year model climatology has been generated using observed SST. Upon successful simulation of climatological features of ISM, the model is tested for the simulation of ISM 2011 in forecast mode. Experiments have been conducted in three different time-phases, viz., April, May and June; using different sets of initial conditions (ICs) and the persistent SSTs of the previous months of the time-phases.

The spatial as well as temporal distribution of model simulated rainfall suggest a below normal monsoon condition throughout the season in all the experiments. However, the rainfall anomaly shows some positive signature over north-east part of India in the month of June and August whereas the central Indian landmass had positive anomaly during August and September. The monthly accumulated AllIndia rainfall (AIR) over land for June to September 2011 are predicted to be $101 \%(17.6 \mathrm{~cm}), 86 \%$ $(24.3 \mathrm{~cm}), 83 \%(21.0 \mathrm{~cm})$ and $95 \%(15.5 \mathrm{~cm})$ of normal AIR, respectively. This makes the seasonal accumulated AIR $78.4 \mathrm{~cm}$ which is $11 \%$ below the normal rainfall of $87.6 \mathrm{~cm}$. The model prediction for the months of June and July is comparable with the observation; however, the simulation would not be able to capture the high rainfall during August and September. The intention behind this work is to assess the shortcomings in the CAM model prediction, which can later be improved for future monsoon forecast experiments.

\section{Introduction}

The word 'Monsoon' is a seasonal long-range weather phenomenon and repeats every year along the entire tropical belt of earth; however, Indian summer monsoon (ISM) has a very special context with respect to India's socio-economic conditions. The socio-economic condition in India is very much dependent on the performance of ISM in terms of excess, deficit or normal rainfall during the month of June to September every year. The rainfall during the summer accounts for almost all the annual rainfall in $75 \%$ of the geographical area and $78 \%$ of the gross cropped area in the country. The seasonal forecasting of ISM rainfall over Indian region has been one of the first targets of tropical climate predictions and is driven by many regional as well as global factors. The most dominant regional factors which mainly affect the ISM are: the differential heating of sea-land, seasonally reversing wind system, large scale cyclonic vorticity at $850 \mathrm{hPa}$, low level westerly jet over the Arabian Sea and the Tibetan anticyclone at the upper level of $200 \mathrm{hPa}$ with the monsoon easterly jet (Charney and Shukla 1981). Further, many large-scale global phenomena like El Niño/La Niña effect or southern oscillations,

Keywords. Summer monsoon; ensemble mean; seasonal forecast; persistent SST anomaly; All-India rainfall. 
Indian Ocean dipole, etc. (Webster and Yang 1992; Kumar et al. 1999; Slingo and Annamalai 2000) are also affecting the seasonal variability of ISM. Other studies (Gadgil et al. 2004) have also shown that anomalies of ISM rainfall are linked to Equatorial Indian Ocean Oscillation between the states of enhancement and suppression of atmospheric convection over the western and eastern parts of the equatorial Indian Ocean and vice versa. These changes are also associated with changes in the anomaly of zonal wind along the equator. The yearly variation of ISM rainfall is primarily associated with the slow varying boundary forcing such as sea surface temperature (SST), sea-ice concentrations, land-snow cover and soil moisture, etc. The seasonal simulation of ISM using a global climate model enables the interaction of the monsoon system with different global attributes like SST variation over Pacific Ocean, Indian Ocean dipole, sea-ice concentration at polar region, etc. On the other hand, the coupled land component of the climate model updates the surface fluxes and exchanges the feedback among different climatic systems with the atmospheric component.

The variation in SST both spatial and temporal plays an important role in intra-seasonal variation of ISM. Many direct and indirect relationships between SST and ISM variability have been argued through the analysis of past observational evidence. Webster et al. (1998) suggested a strong relationship between the equatorial eastern Pacific SST and ISM rainfall intensity. Lau and Yang (1996) find a negative correlation of -0.5 between the ISM rainfall and the equatorial eastern Pacific SST and a small positive correlation of 0.2 with the equatorial Indian Ocean SST. It suggests that the ISM rainfall is more sensitive towards the events around the eastern Pacific Ocean such as El Niño/La Niña rather than the Indian Ocean SST. However, despite the above tele-connections, during 1997-1998, one of the recent strongest El Niño episodes could not affect the Indian monsoon rainfall significantly. ISM for the year 1997 has been recorded as slightly above normal. Several hypothesis and theories that came up in supporting this event, like, the variations of Walker and Hadley circulations forced by the equatorial Pacific SST anomalies (Slingo and Annamalai 2000) and Eurasia surface warming (Kumar et al. 1999). Further, the changes in global climate have also some hidden but significant impact on ISM in the recent years. The trend of wind circulation and rainfall distribution around Indian landmass on the recent ISMs shows significant variations from the ISM climatology (Francis and Gadgil 2010). The study by Gadgil and Srinivasan (2011) has demonstrated the performance of different dynamical models for the seasonal prediction of ISM with observed as well as April persistence SST anomaly for several years with mixed success.

The seasonal forecasting of ISM rainfall using the dynamical model CAM3 has been carried out in 2011 at Space Applications Centre (SAC), Ahmedabad during the progress of different phases of the monsoon. Before using the CAM3 model directly for seasonal prediction; the model has been tested at T85L26 resolution, which is equivalent to 1.4 degrees horizontal resolution with 26 unequal vertical levels using observed SST and observed sea-ice concentrations for the characterization of mean simulated features. The land component of the CAM3 model has also been tested both in standalone and coupled mode with CAM3 and the climatological monsoon rainfall peak has been captured satisfactorily by the model climatology (Das et al. 2011). A 30-year model climatology and large number of seasonal forecasting experiments for the year 2009 and 2010 have also been performed using observed and persistence SST in hind-cast mode. During the analysis of model climatology, a systematic rain-bias has been observed and removed by statistical bias correction technique that is being plugged along with the model configuration (figure 1). The rain-bias correction methodology, the validation of model generated rainfall climatology along with a glimpse of seasonal rainfall forecast (without any validation) for ISM 2011 for a single ensemble CAM experiment during the June-phase were discussed in the earlier work (Das et al. 2012). However, there was no scope for the detailed analysis of all seasonal forecast experiments of ISM 2011 which had been done in three experimental phases during April, May and June, respectively.

The present work is a continuation of Das et al. (2012), with slight difference in objective. The actual performance of different phases of forecast experiments sensitive towards the different persistent SSTs when compared with observations is the main focus of the work. The motivation for the present work is: upon reasonable successes on the performance of CAM3 model for the simulation of ISM during the hind-cast simulation (Das et al. 2012), to see the performance of CAM3 model for the prediction of ISM in the forecast mode and also to assess the sensitivity of different persistent SST anomaly for the prediction of ISM 2011 rainfall. In doing so the CAM3 model is being used first time for the seasonal prediction experiments in the year 2011 on an experimental basis during different phases of the progress of monsoon. Subsequently after completion of the monsoon period of 2011, the different phases of prediction results are validated with observation to enlist the shortcoming in the model. All the prediction experiments, the results of which are discussed in this study, 


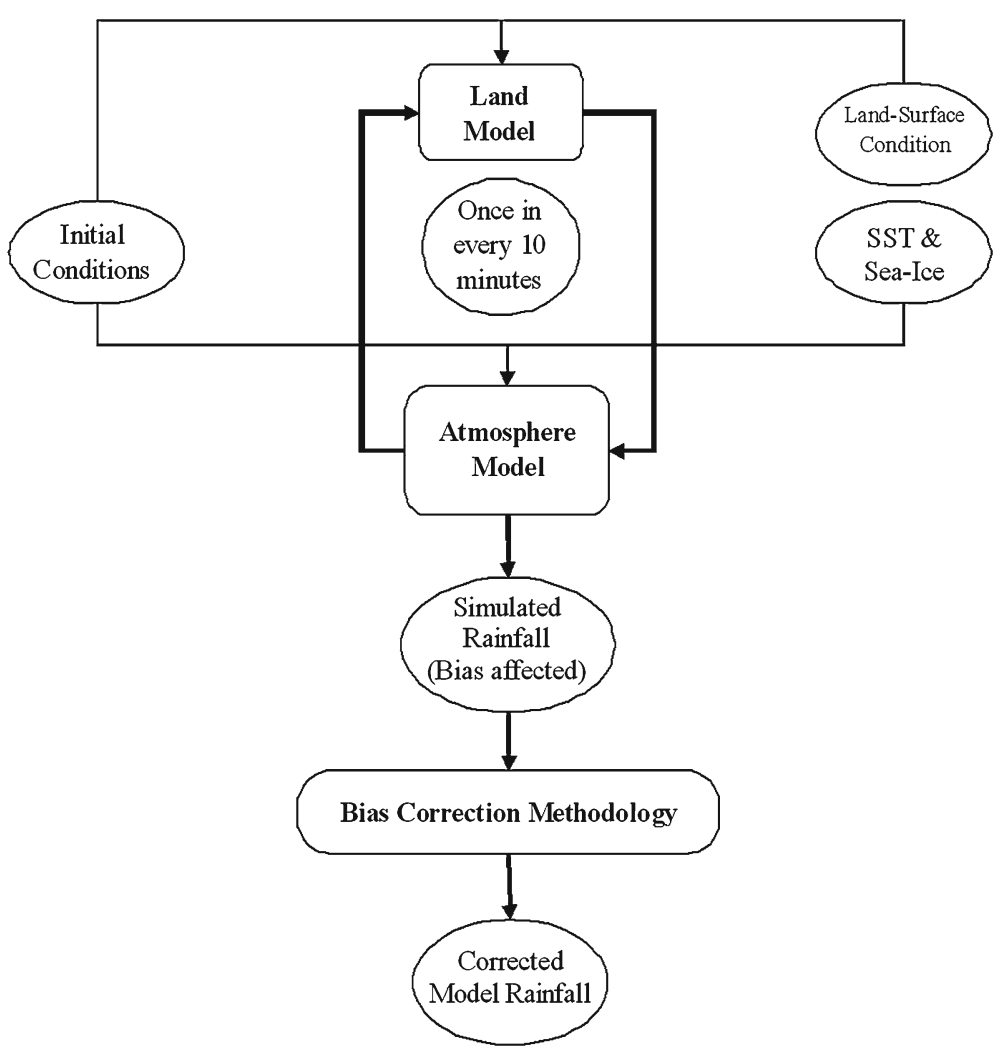

Figure 1. Block diagram of the atmospheric model CAM with bias correction methodology.

were performed in the forecast mode. Following section 2 describes briefly the observed features of ISM 2011, while brief details about the model, data and experimental design are discussed in section 3. Section 4 discusses the performance of the model prediction experiments and section 5 summarizes the conclusion from the present study.

\section{Salient features of ISM 2011}

The ISM 2011 was unique for the temporal variations of rainfall along the monsoon months, i.e., June to September (Tyagi and Pai 2012). The first part of the monsoon (June-July) experienced below normal rain over Indian landmass whereas in the second part (August-September), it measured well above normal, which made overall slightly above normal monsoon of the whole season for the year 2011. The most notable fact of ISM 2011 was that the peak of the rain-rate had been observed in mid-August; further the August accumulated rain over Indian landmass was significantly high compared to July. The surface temperature over the east equatorial Pacific Ocean and North Pacific Ocean along $40^{\circ} \mathrm{N}$ influences the monsoon circulations and the rainfall pattern over Indian landmass for ISM 2011. The temperature differences between the first phase of ISM (June--July) and later phase of it (August-September) over Pacific Ocean is quite different. The differences in temperature as experienced by ISM during 2011 shows $0.5^{\circ}-1.0^{\circ}$ less in magnitude compared to the climatological temperature difference between the monsoon phases over Pacific regions. The accumulated AllIndia rainfall (AIR) in the first part of the season (June-July) shows 5\% deficient whereas August-September duration measured 17\% excess compared to the normal AIR. As per India Meteorological Department (IMD) gridded observations, the monthly accumulated AIR over land for June to September 2011 are $106 \%$ (18.4 cm), $89 \%$ $(25.3 \mathrm{~cm}), 116 \%(29.4 \mathrm{~cm})$ and $120 \%(19.6 \mathrm{~cm})$ of normal AIR, respectively which makes the seasonal accumulated AIR $92.7 \mathrm{~cm}$ which is $6 \%$ above the normal rainfall of $87.6 \mathrm{~cm}$ (table 2 ).

\section{Model description and experiment design}

\subsection{The CAM model}

The Community Atmosphere Model version 3 (CAM3) is an atmospheric general circulation model (AGCM) developed from the older version of National Center for Atmospheric Research (NCAR) Community Climate Model (CCM) with significant changes in dynamical core (Collins et al. 2006), the treatment of cloud and precipitation 
processes (Boville et al. 2006), radiation processes (Collins et al. 2002a) and atmospheric aerosols (Collins et al. 2002b). A block diagram of the model can be seen in figure 1 . The surface data over land are exchanged between atmosphere and land component of the CAM model at every 10 modelminutes. The dynamical core of CAM3 is based on the Eulerian spectral dynamics with triangular spectral truncation at different wave-numbers, viz., 31, 42, 85, 170, etc. The zonal resolution at the equator varies from $3.75^{\circ}$ to $1.41^{\circ}$ in T31 and T85 configurations. A hybrid terrain-following vertical coordinate with 26 levels are followed in the vertical dimension.

The Community Land Model (CLM) developed at NCAR, coupled with CAM3 model, is served as the land component of atmospheric model. Though both atmosphere and land models are integrated on the same horizontal grid, each grid of CLM is further divided into a hierarchy of land units, soil columns, and plant functional types (PFT). The land model is comprised of vegetated surface up to 17 pre-defined PFTs including the bare ground. These PFTs differ in physiological and morphological traits along with climatic preferences as well as leaf and stem optical properties (Bonan et al. 2002). The more details about CLM have been discussed by Dickinson et al. (2006).

\subsection{Experiment design and data used}

In the present study, a seasonal prediction of ISM 2011 has been attempted with ensemble CAM simulations using persistent SST anomaly (PSA) with different sets of initial conditions (IC) (table 1) at three different phases, viz., April, May and June (represented as Exp-01, Exp-02 and Exp-03, respectively). The first set of experiment had been conducted in April (Exp-01) using the March PSA with 10-member ensemble set, while the second and third phases of experiment during May (Exp02) and June (Exp-03) using the April and May PSA for each 10-member ensemble set respectively. The PSA of respective months has been used in all the phases of the experiments with the assumption that this anomaly will continue to persist throughout the monsoon season. The ISM simulation of 2011 using different persistence of SST anomaly has been carried out to assess the impact of persistent SST on the forecast skill of the model. However, only one year forecast of ISM using PSA will not establish the model credibility that needs a series of forecast for many more years, but the present analysis will give the confidence about the model as well as measuring the effectiveness of the PSA assumption on seasonal forecast of ISM.

The different surface data for each land grid cell are glacier, lake, wetland, and urban portions of the grid cell; the fractional cover of the four most abundant PFTs in the vegetated portion of the grid cell; monthly leaf and stem area index and canopy top and bottom heights for each PFT; soil colour and soil texture. These fields are taken from International Geosphere-Biosphere Program (IGBP) landsurface datasets and interpolated to model grid from high resolution datasets. The land component of the model has been initialized through an initial land-atmosphere coupled simulation for one year using specific land surface conditions taken from IGBP climatological dataset and not for the year 2011. This is one limitation of the present version of land component of the model. Each land grid cell has been further initialized with the land type, land color, PFT vegetation type, ground temperature, soil water at 10 subsurface layers and snow depth. The atmospheric component has also been initialized with gridded temperature, humidity and wind profiles in 26 vertical layers in the atmosphere, surface pressure, surface temperature and PBL height. The model IC dataset has been taken from National Center for Environmental Prediction (NCEP) analysis with $1^{\circ} \times 1^{\circ}$ resolution, interpolated into model resolution. The global monthly optimum interpolation SST (OI SST) of $1^{\circ} \times 1^{\circ}$ resolution (Reynolds et al. 2002 ) taken from National Oceanic and Atmospheric Administration (NOAA) has been used to calculate the persistent SST used as boundary condition in all the experiments. The validation of model forecasted rainfall has been carried out with the Kalpana satellite derived rain product named INSAT multi-spectral rainfall algorithm (IMSRA) (Prakash et al. 2010). The IMD in-situ observed daily gridded $1^{\circ} \times 1^{\circ}$

Table 1. Experiment design for seasonal forecast of ISM-2011.

\begin{tabular}{lcl}
\hline $\begin{array}{l}\text { Experiment } \\
\text { and time-phase }\end{array}$ & $\begin{array}{c}\text { 10 initial conditions (ICs) } \\
\text { used (each at 00 UTC) }\end{array}$ & $\begin{array}{c}\text { SST boundary condition } \\
\text { used (till September) }\end{array}$ \\
\hline Exp-01, April & $22-31$ March & March SST anomaly \\
Exp-02, May & $21-30$ April & April SST anomaly \\
Exp-03, June & $22-31$ May & May SST anomaly \\
\hline
\end{tabular}

Note: Each experiment has 10 ensemble members and the model integration time is from the specific IC date to September for all experiments. 
rainfall (Rajeevan and Bhate 2009) has been used specifically for validation over Indian landmass. Tropical Rainfall Measuring Mission (TRMM) monthly rain product TB42 is not used here for the validation purpose because it has been used for the model rain-bias correction.

\section{Results and discussions}

The seasonal mean rain-rate from different experiments, viz., Exp-01, Exp-02 and Exp-03 have been generated through the ensemble mean after the rain-bias corrections (Das et al. 2012) in each member of the ensemble and compared with IMSRA and IMD in-situ gridded rain observations. Highly outlier members compared to other members of the family have been excluded during the computation of ensemble mean. This has been performed in the grid box level in two steps. First, the mean and standard deviation (SD) of rain-rate at each grid box has been computed and the member has been marked as outliers for that particular grid box if the member fails to lie within the interval (mean $\pm 2.5 \times \mathrm{SD}$ ). In the second step, recomputation of the mean and SD has been performed by excluding the outlier members for the concerned grid box. The procedure will eliminate the influence of any sudden high (low) rain in a grid box of one member compared to all other members which excludes on an average of $2-5 \%$ ensemble members of rain-grid points.

The analysis results for Exp-01 have less significant signal on the forecast as it has been conducted with the PSA for the month of March which is well before the monsoon season June-September. The assumption of persistency in SST anomaly has been found weakening with time. Figure 2 shows the ensemble seasonal average rain-rate from the Exp-01, Exp-02 and Exp-03 (i.e., the April, May and June phases) along with Kalpana satellite
June-July Average Rainfall

(a)

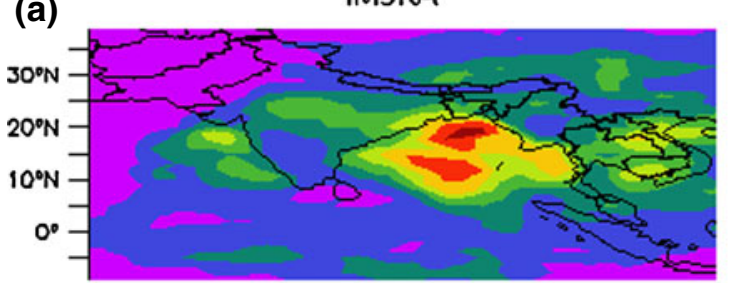

(c)

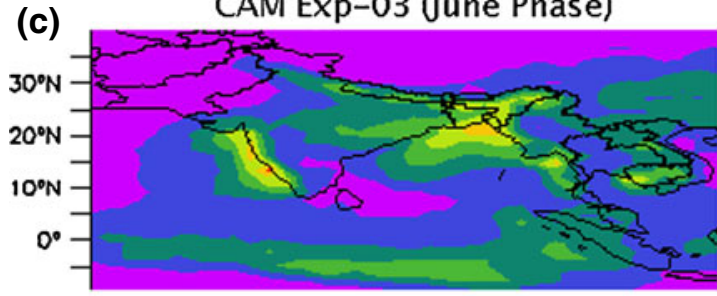

(e) CAM Exp-02 (May Phase)
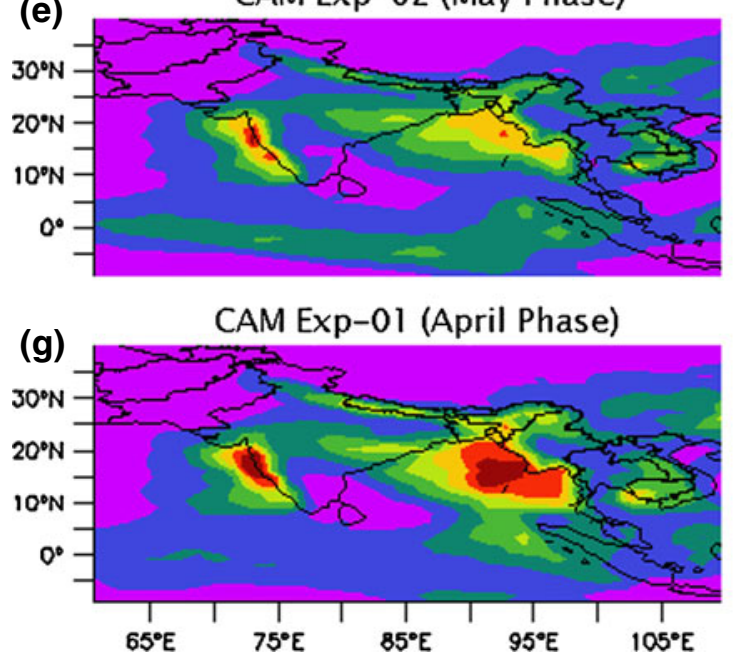

Aug-Sept Average Rainfall

(b) IMSRA

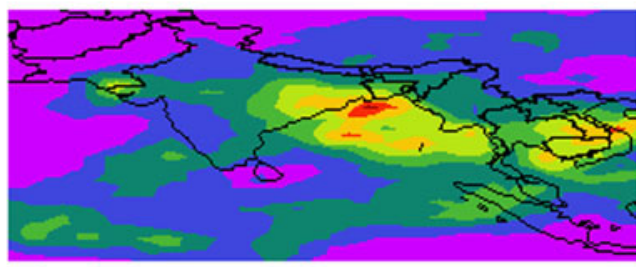

(d)

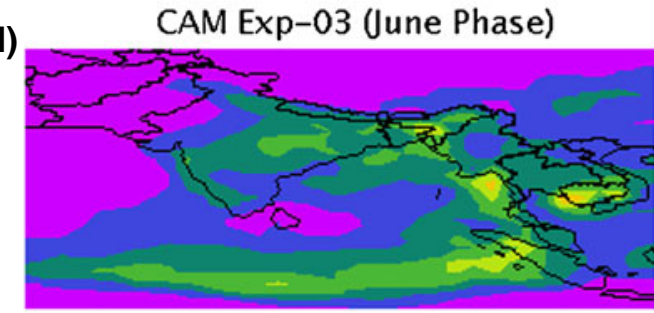

(f)

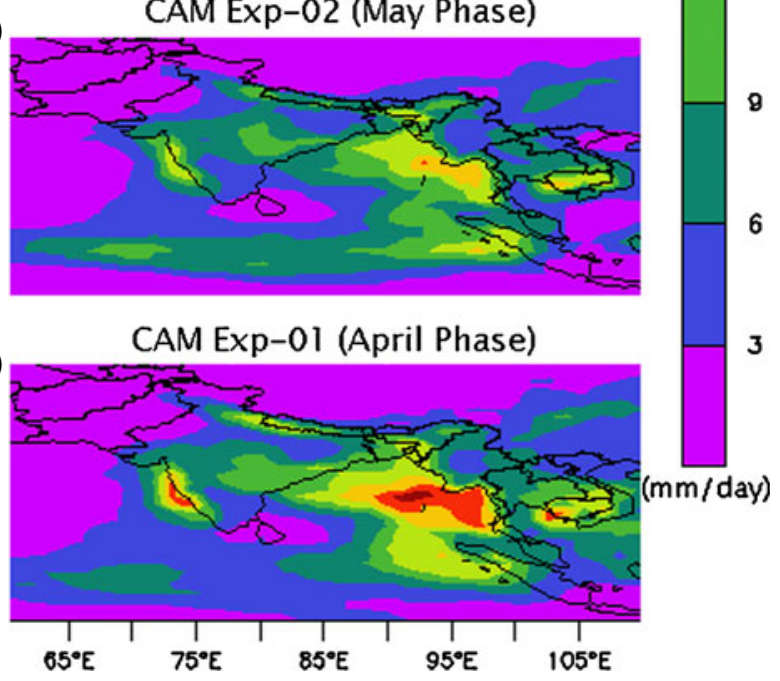

Figure 2. Comparison of model simulated rainfall with Kalpana satellite derived IMSRA rain; left panel shows June--July average and the right panel shows August-September average rainfall. 
derived IMSRA rain-rate over Indian region averaged for June-July (left panel) and AugustSeptember (right panel), respectively. The rainrates over central India and southern part of India are comparable; however, the model has highly underestimated rain-rate over the Bay of Bengal region. The high rain-rate along the Western Ghats and the foothills of Himalaya can be seen in model forecast in all the experiments which is less prominent in the IMSRA rain-rate. The IMSRA retrieved rain-rate from Kalpana has some limitations over the Western Ghats and the foothills of Himalaya due to land topography problem (Prakash et al. 2010). It can further be seen from the figure that both the experiments Exp-02 and Exp-03 are able to capture the first part of the monsoon (JuneJuly, left panel) quite well in comparison to the IMSRA rain. However, the excess rainfall over the central and eastern part of India cannot be captured by the experiments; though the Exp-03, June phase shows a better match in variation of rain-rate during the analyzed months. Figure 3 shows the difference between the forecasted rain from the Exp-03 and the IMD in-situ gridded observations accumulated for the months from June to September. The Exp-03 has underestimated the accumulated rain along the Western Ghats for all the months and the foothills of Himalaya in August. The central India and the eastern part of India also show some underestimation during the peak monsoon period. However, the southern part of India has a good resemblance with the IMD observations in the monsoon months.

The spatial pattern correlation coefficients of monthly averaged AIR between the experiments and IMD in-situ observations have been computed (figure 4) with a 95\% confidence interval using the following formula. The sample Pearson product-moment correlation is

$$
r_{x y}=\frac{\sum_{i, j}\left(x_{i j}-\bar{x}\right)\left(y_{i j}-\bar{y}\right)}{\sqrt{\sum_{i, j}\left(x_{i j}-\bar{x}\right)^{2} \sum_{i, j}\left(y_{i j}-\bar{y}\right)^{2}}},
$$

(a) Rain Diff. [Model - IMD] June 2011

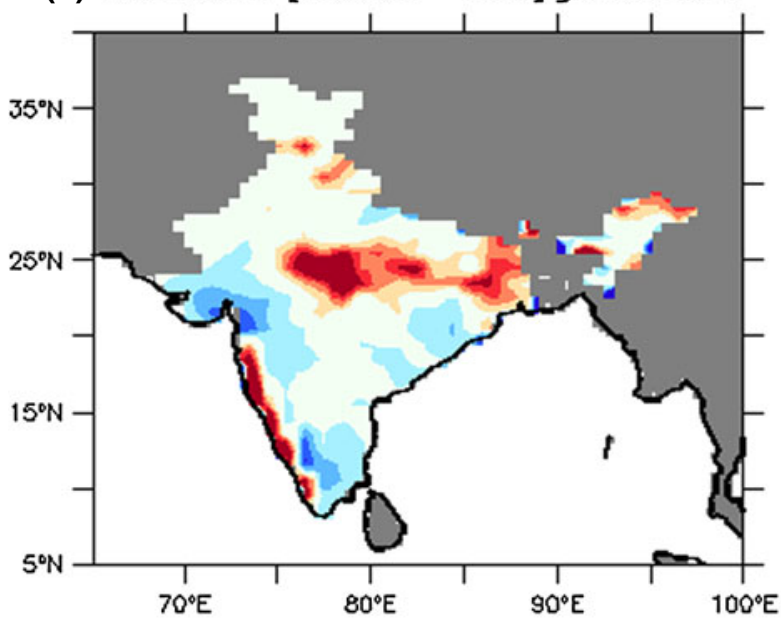

(c) Rain Diff. [Model - IMD] Aug 2011

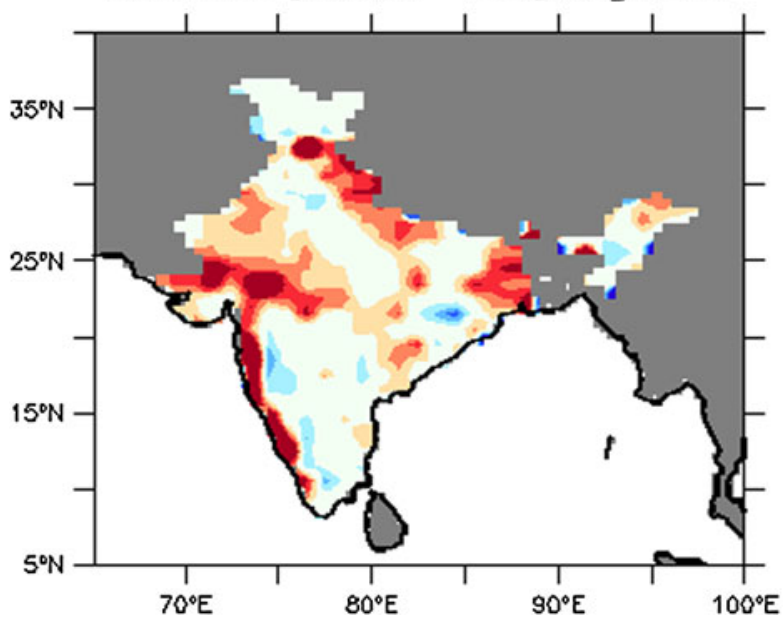

(b) Rain Diff. [Model - IMD] July 2011

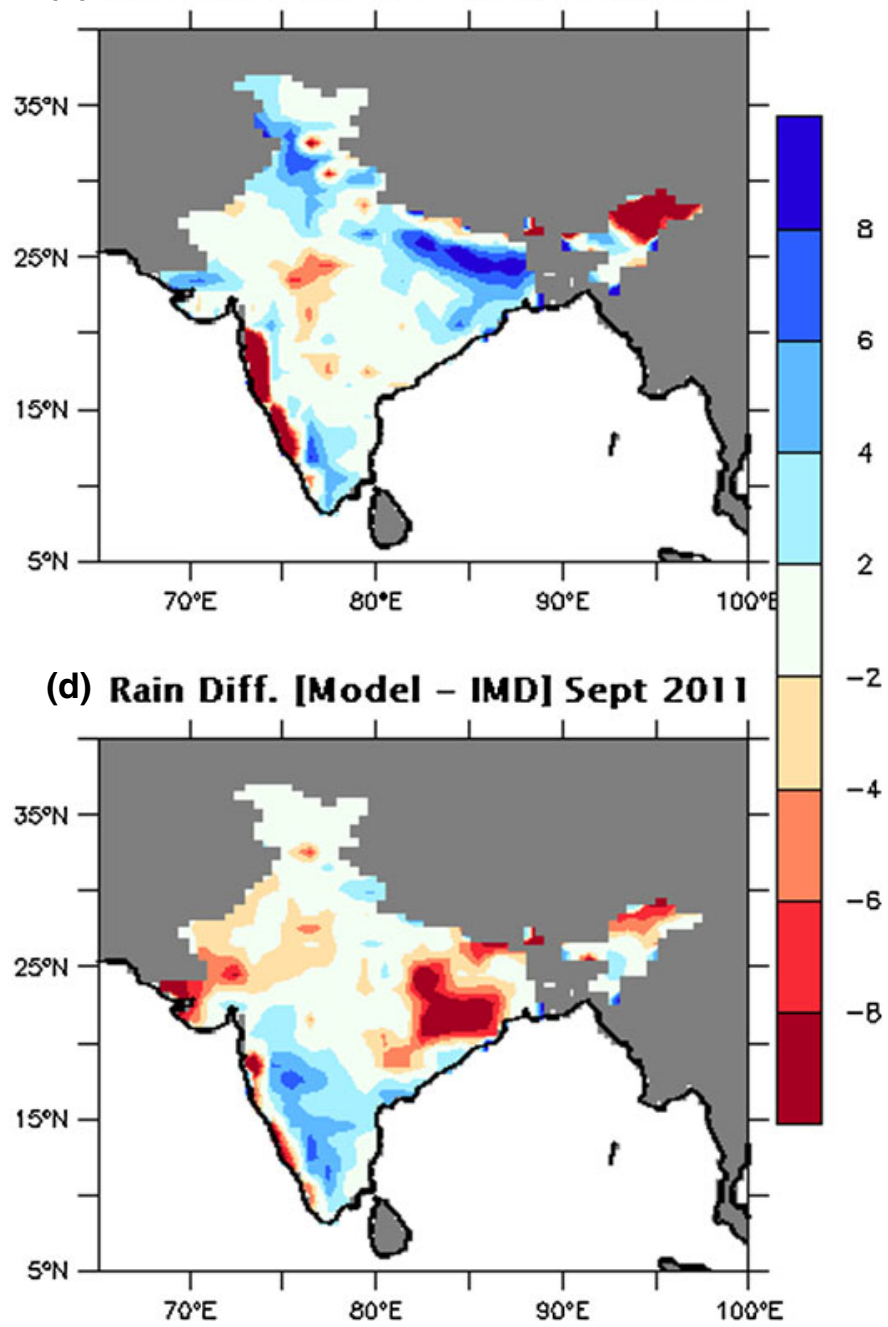

Figure 3. Difference of model forecast monthly rainfall from June phase (Exp-03) and IMD in-situ gridded observations. 

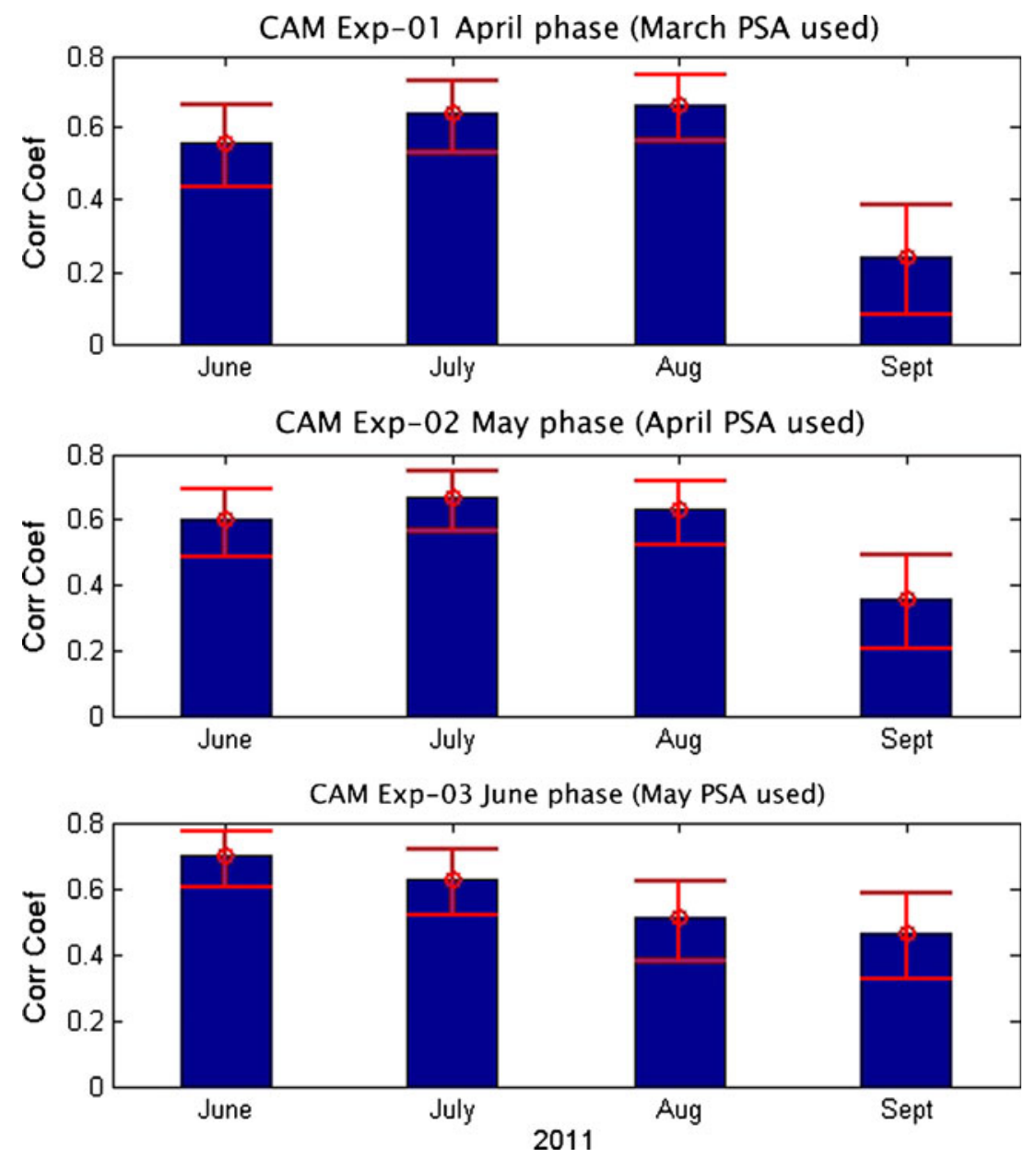

Figure 4. Correlation coefficients of monthly AIR between CAM ensemble rain-rate simulated by different time-phase experiments and gridded IMD in-situ observations for ISM-2011; the red line denotes the $95 \%$ confidence interval.

where $x_{i j}$ and $y_{i j}$ are the CAM ensemble rainrate and gridded IMD in-situ observation for the grid-box $(i, j)$ respectively. Further, $\bar{x}=$ $\sum_{i, j} x_{i j} / N$ is mean CAM rain, $\bar{y}=\sum_{i, j} y_{i j} / N$ is mean IMD rain and $N$ is the total number of grid-box. The $95 \%$ confidence interval for correlation coefficient $\rho$ has been computed based on the sample correlation coefficient $r_{x y}$ after applying the Fisher transformation $z=0.5 \log _{e}(1+r / 1-r)$. The distribution of $z$ is not strictly normal, but it tends to be normal rapidly as the sample size increases for any values of $\rho$. Figure 4 shows that the correlations during August and September are noticeably low compared to June-July in all the experiments. Also the $95 \%$ confidence intervals for AugustSeptember are more widely spread in all experiments. The Exp-03 shows a perfect case in which the correlation decreases with time; indicating the validity of the assumption of persistent SST decay with time during the monsoon months; and it is observed to be the best prediction among all the experiments conducted. However, in the second phase, Exp-02 also produced a steady correlation through the monsoon months from June to August 2011. A direct comparison between the three phases of experiment and IMD in-situ observation along with climatological AIR computed for each month June through September can be seen in table 2. The first half of the monsoon (June-July) has been captured by the model forecast; however, the August and September high rainfall (16\% and $20 \%$ respectively) has not been captured by any of the experiments.

Figure 5 shows the time evolution (monthly) of model estimated ensemble rain AIR during JuneSeptember compared with the IMD gridded insitu observations over different parts of India. Important variations in different regional rainfall patterns can be seen in both the observation and simulation. The north-east part of India experience very high rainfall in the month of June compared to the other regions, can be seen in the IMD rain (blue line), but the simulation failed to produce such 
differences. The unexpected high rainfall recorded throughout the country in the month of August, also could not be seen in the simulations; however a few members of the ensemble family have been able to capture the high rain patterns in August, specifically over the southern India. On an average, the model prediction for the months June-September has been able to produce the correlation of 0.61

Table 2. Monthly and seasonal all-India rainfall of simulated and IMD in-situ observations for 2011.

\begin{tabular}{lccccc}
\hline & $\begin{array}{c}\text { Exp-01 } \\
\text { (April phase) }\end{array}$ & $\begin{array}{c}\text { Exp-02 } \\
\text { (May phase) }\end{array}$ & $\begin{array}{c}\text { Exp-03 } \\
\text { (June phase) }\end{array}$ & $\begin{array}{c}\text { IMD observed } \\
\text { for 2011 }\end{array}$ & $\begin{array}{c}\text { Climatology } \\
\text { IMD (CAM) }\end{array}$ \\
\hline June 2011 & $18.8(+8 \%)$ & $17.8(+2 \%)$ & $17.6(+1 \%)$ & $18.4(+6 \%)$ & $17.4(18.3)$ \\
July 2011 & $27.5(-3 \%)$ & $25.5(-10 \%)$ & $24.3(-14 \%)$ & $25.3(-11 \%)$ & $28.4(27.1)$ \\
August 2011 & $25.0(-2 \%)$ & $23.2(-9 \%)$ & $21.0(-17 \%)$ & $29.4(+16 \%)$ & $25.4(23.1)$ \\
September 2011 & $18.4(+12 \%)$ & $15.5(-5 \%)$ & $15.5(-5 \%)$ & $19.6(+20 \%)$ & $16.4(17.3)$ \\
Seasonal (June-September) & $89.7(+2 \%)$ & $82.0(-6 \%)$ & $78.4(-11 \%)$ & $92.7(+6 \%)$ & $87.6(85.8)$ \\
\hline
\end{tabular}

Note: All figures are in $\mathrm{cm}$.

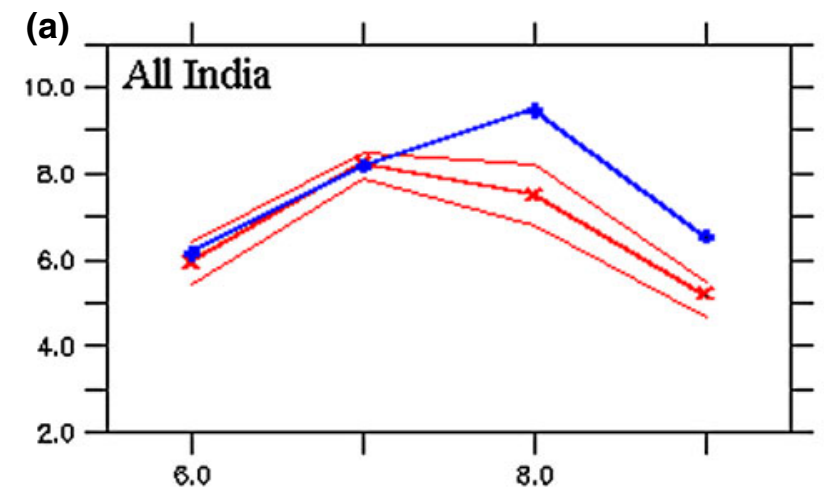

Blue line $(\rightarrow)$ ) is ground observed (IMD) AIR Red line $(x, m$,$) is ensemble model prediction (CAM)$ Light red boundary lines described regions that include $90 \%$ of the ensemble members AIR
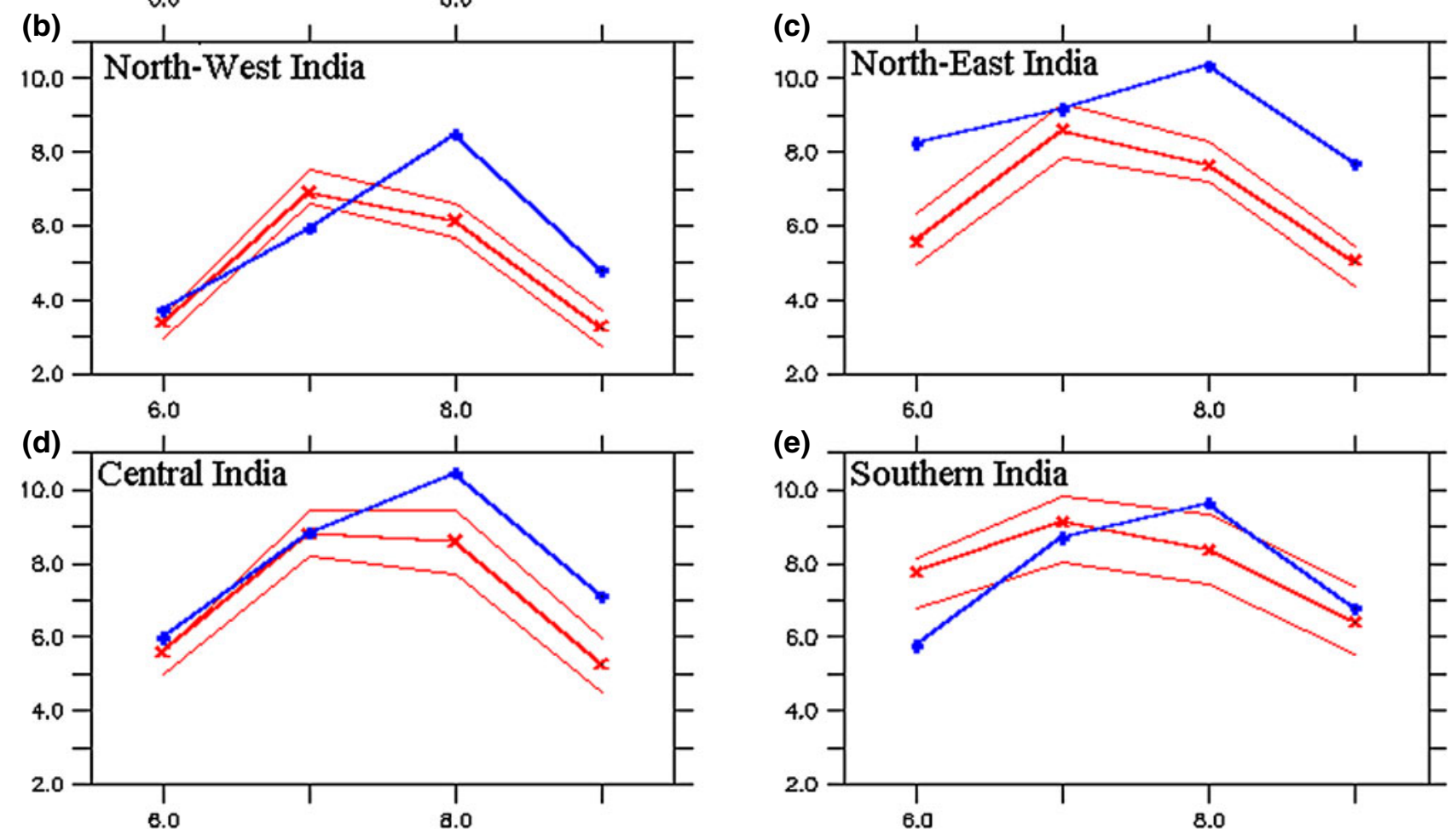

Figure 5. Time evolution of AIR simulated by April persistent SST experiment (red line) along with the red boundaries covering $90 \%$ of the ensemble members lying within the region compared with the IMD in-situ observations derived AIR (blue line) over different zones of India. 
with the IMD in-situ gridded observations, compared to the correlation of 0.68 between the model climatology and IMD in-situ observations for 2011; however, the model has performed quite well producing correlation of 0.67 during the first phase of monsoon, i.e., June--July.

In assessing the model performance, it is important to identify the role of PSA on seasonal forecasting. The ensemble simulation is highly sensitive to the SST fields used as boundary conditions. In the case of ISM-2011, some unexpected temperature differences over the Pacific Ocean can be identified during the second phase of the monsoon (figure 6). The upper panel (figure 6a) shows the comparison of difference in SST of the two phases of the monsoon, viz., June--July and AugustSeptember between the climatological or PSA condition (used in the model simulations) and the observed seasonal SST for 2011. The lower panel (figure 6b) shows the time evaluation of the difference in SST between persistent and observed from June to September along latitude (left) as well as longitude (right) for the Exp-01, Exp-02 and Exp-03 in three respective rows. It can be seen from the figure that, the persistent SST does not change much during April-May-June whereas it significantly differs from the persistency in August-September. Further, the warm-pool region developed at around $20^{\circ} \mathrm{N}$ during April-May is propagated northward and intensified with time up

(a) Difference in SST during Monsoon Season (AugSept Average - JuneJuly Average)
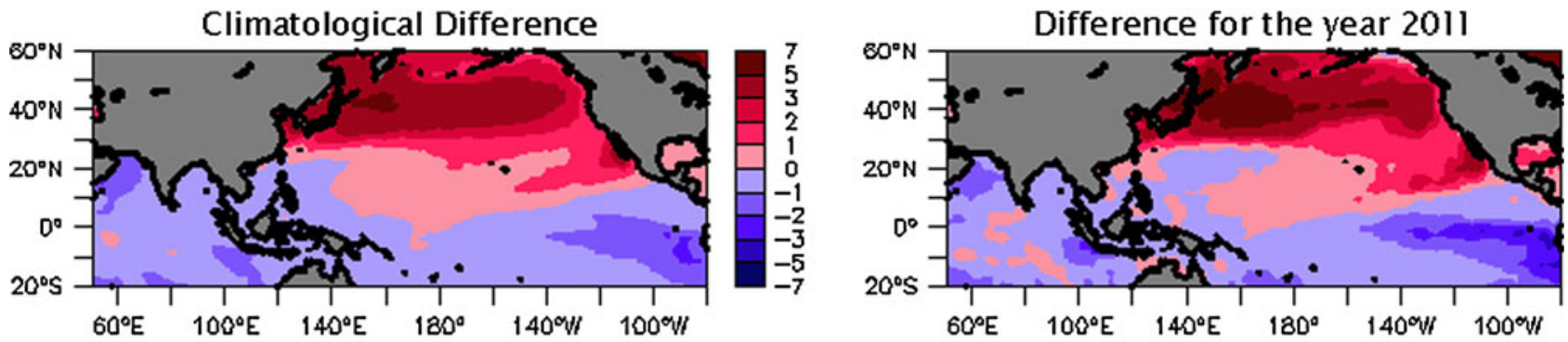

(b) Time Evaluation of SST along Latitude \& Longitude (Observed SST - Persistent SST)
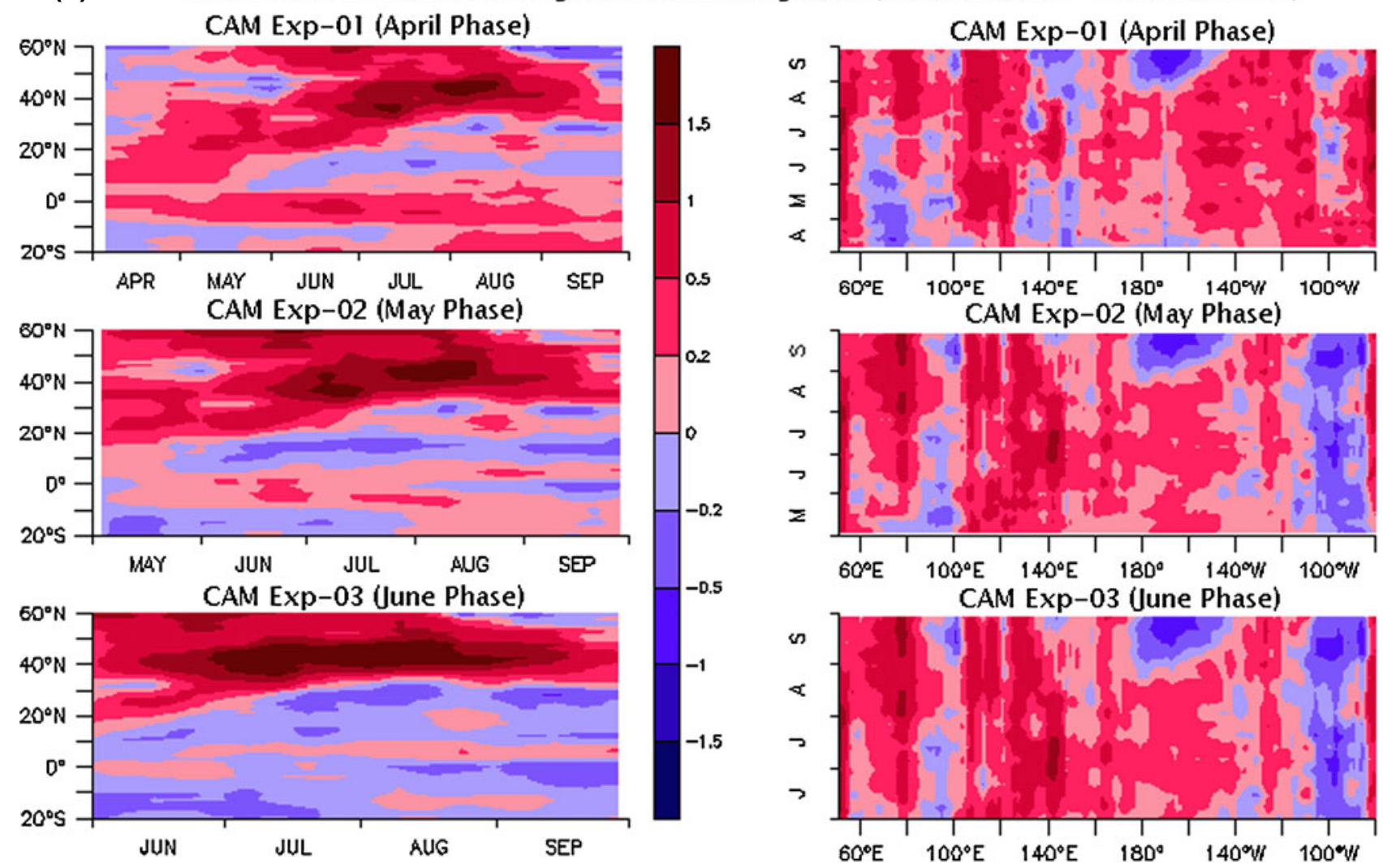

Figure 6. Comparison of persistent SST and observed SST for the year 2011 during June to September. 
to $2 \mathrm{~K}$ around $40^{\circ} \mathrm{N}$ that can be seen in the left panel 2nd row of figure 6. It is difficult to predict the evolution of SST in the latter part of the monsoon (August-September) especially over the Pacific Ocean where El Niño/La Niña effects are dominating.

The spatial and temporal variation of SST is certainly one of the dominating factors in the prediction of ISM; however, there are several other factors that may lead to significant deviations in model prediction from the observations. The state of land surface conditions, viz., moisture available on the surface, land cover-land use information and the differential heating of land-sea also play important role in estimating the ISM rainfall. All these factors will be taken care of in the future ISM prediction experiment.

\section{Conclusion}

The seasonal forecast of the Indian summer monsoon 2011 using the CAM model with 10-member ensemble has been attempted. The experiments have been conducted in three time-phases, viz., April (Exp-01), May (Exp-02) and June (Exp-03) using the current SST anomaly observed in the previous months of the respective time phases. The performance of seasonal forecast is highly influenced by the assumption of persistency of SST anomaly during the monsoon period. The monthly AIRs from the May (Exp-02) and June (Exp-03) phases of the experiment are comparable (table 2). Although the monthly accumulated AIR from May phase has a better agreement with the IMS in-situ gridded observations compared to the June phase (table 2), the June phase shows high spatial correlations of monthly AIR with IMD (figure 3).

In the first half of the monsoon (June-July), the monthly forecast of rainfall from June phase are $101 \%$ (June) and 86\% (July) of normal; IMD insitu observations show June 106\% and July $89 \%$ of normal. However, during the months of AugustSeptember, model forecast shows $5 \%$ and $11 \%$ deficiency in monthly rainfall, whereas IMD measures excess of $20 \%$ and $6 \%$ of normal for the months of August and September. The difference in actual and predicted rainfall may be due to the use of persistence SST anomaly during the peak monsoon months. The major limitation of the present study is that it looks the seasonal prediction of ISM rainfall with the prospective of looking at persistence SST only. The impact of persistence SST along with soil moisture, snow cover and other land surface parameters in the atmosphere-land coupled system may give some insight into the problem of seasonal forecasting of ISM rainfall.
Once again, the present study is just for one year of experimental prediction, many more years of analysis is required to find a concrete reason for the difference.

\section{Acknowledgements}

The authors are thankful to the anonymous reviewers for their critical and insightful comments and suggestions which have significantly improved the quality and presentation of the manuscript. Authors are thankful to the NCAR for providing the source code of CAM3 model. The Director and the Deputy Director-EPSA of Space Applications Centre (SAC), ISRO, Ahmedabad are thanked for their encouragement and help. The authors are thankful for the excellent computer facility provided at AOSG. The NCEP are thankfully acknowledged for providing the analysis for preparing the model initial conditions. The authors are thankful to Dr R M Gairola and Dr M Rajeevan for providing Kalpana derived IMSRA rain and gridded rainfall from IMD respectively for validation.

\section{References}

Bonan G B, Levis S, Kergoat L and Oleson K W 2002 Landscapes as patches of plant functional types: An integrating concept for climate and ecosystem models; Global Biogeochemical Cycles 16 5.1-5.23.

Boville B A, Rasch P J, Hack J J and McCaa J R 2006 Representation of clouds and precipitation processes in the Community Atmosphere Model version 3 (CAM3); J. Clim. 19 2184-2198.

Charney G J and Shukla J 1981 Predictability of monsoons; In: Monsoon dynamics (eds) Lighthill J and Pearce R P, Cambridge University Press, pp. 99-109, 13: 4366-4377.

Collins W D, Hackney J K and Edwards D P 2002a A new parameterization for infrared emission and absorption by water vapor in the National Center for Atmospheric Research Community Atmosphere Model; J. Geophys. Res. 107 8028, doi: 10.1029/2001JD001365.

Collins W D, Rasch P J, Eaton B E, Fillmore D W, Kiehl J T, Beck T C and Zender C S 2002b Simulation of aerosol distributions and radiative forcing for INDOEX: Regional climate impacts; J. Geophys. Res. 107 4664, doi: 10.1029/ 2001JD001365.

Collins W D et al. 2006 The formulation and atmospheric simulation of the community atmosphere model version 3 (CAM3); J. Clim. 19 2144-2161.

Das S K, Deb S K, Kishtawal C M, Joshi P C and Pal P K 2011 Climate change studies using coupled model: Land surface perspective; J. Indian Soc. Remote Sens. 39(3) 323-336, doi: 10.1007/s12524-011-0111-5.

Das S K, Deb S K, Kishtawal C M and Pal P K 2012 Assessment of Indian summer monsoon simulation by community atmosphere model (CAM3); Theor. Appl. Climatol. 109 81-94, doi: 10.1007/s00704-011-0565-y.

Dickinson R E, Oleson K W, Bonan G B, Hoffman F M, Thornton P E, Vertenstein M, Yang Z L and Zeng X B 2006 The community land model and its climate statistics as a component of the community climate system model; J. Clim. $192302-2324$. 
Francis P A and Gadgil S 2010 Towards understanding the unusual Indian monsoon in 2009; J. Earth Syst. Sci. 119(4) 397-415.

Gadgil S, Vinayachandran P N, Francis P A and Gadgil S 2004 Extremes of the Indian summer monsoon rainfall, ENSO and equatorial Indian Ocean oscillation; Geophys. Res. Lett. 31 L12213, doi: 10.1029/2004GL019733.

Gadgil S and Srinivasan J 2011 Seasonal prediction of Indian monsoon; Curr. Sci. 100(3) 343-353.

Kumar K K, Rajagopalan B and Cane M A 1999 On the weakening relationship between the Indian monsoon and ENSO; Science 284 2156-2159.

Lau K M and Yang S 1996 The Asian monsoon and predictability of the tropical ocean-atmosphere system; Quart. J. Roy. Meteorol. Soc. 122 945-957.

Prakash S et al. 2010 Estimation of Indian summer monsoon rainfall using Kalpana-1 VHRR data and its validation using rain gauge and GPCP data; Meteor. Atmos. Phys. $11045-57$.
Rajeevan M and Bhate J 2009 A high resolution daily gridded rainfall dataset (1971-2005) for mesoscale meteorological studies; Curr. Sci. 96(4) 558-564.

Reynolds R W, Rayner N A, Smith T M, Stokes D C and Wang W 2002 An improved in-situ and satellite SST analysis for climate; J. Clim. 15 1609-1625.

Slingo J M and Annamalai H 2000 1997: The El Niño of the century and the response of the Indian summer monsoon; Mon. Weather Rev. 128.

Tyagi A and Pai D S 2012 Monsoon 2011: A Report; IMD Met. Monograph No: Synoptic Meteorology No. $01 / 2012$.

Webster P J and Yang S 1992 Monsoon and ENSO: Selectively interactive systems; Quart. J. Roy. Meteorol. Soc. 118 877-926.

Webster P J, Magana V O, Palmer T N, Shukla J, Tomas R A, Yanai M and Yasunari T 1998 Monsoons: Processes, predictability and the prospects of prediction; J. Geophys. Res. 103(C7) 14451-14510. 